Hydrol. Earth Syst. Sci., 13, 2179-2190, 2009

www.hydrol-earth-syst-sci.net/13/2179/2009/

(c) Author(s) 2009. This work is distributed under

the Creative Commons Attribution 3.0 License.

\title{
Footprint issues in scintillometry over heterogeneous landscapes
}

\author{
W. J. Timmermans ${ }^{1}$, Z. Su ${ }^{1}$, and A. Olioso ${ }^{2}$ \\ ${ }^{1}$ International Institute for Geo-information Sciences and Earth Observation, Dept. of Water Resources, P.O. Box 6, 7500 \\ AA, Enschede, The Netherlands \\ ${ }^{2}$ UMR 1114 INRA-UAPV Environnement Méditerranéens et Modélisation des AgroHydrosystèmes (EMMAH), \\ Site Agroparc, Domaine St. Paul 84914 Avignon Cedex 9, France
}

Received: 14 February 2009 - Published in Hydrol. Earth Syst. Sci. Discuss.: 9 March 2009

Revised: 1 September 2009 - Accepted: 26 September 2009 - Published: 12 November 2009

\begin{abstract}
Scintillometry is widely recognized as a potential tool for obtaining spatially aggregated sensible heat fluxes at regional scales. Although many investigations have been made over contrasting component surfaces, few aggregation schemes consider footprint contributions. In this paper, an approach is presented to infer average sensible heat flux over a very heterogeneous landscape by using a large aperture scintillometer. The methodology is demonstrated on simulated data and tested on a time series of measurements obtained during the SPARC2004 experiment in Barrax, Spain. Results show that the two-dimensional footprint approach yields more accurate results of aggregated sensible heat flux than traditional methods.
\end{abstract}

\section{Introduction}

Spatial variation in land surface sensible heat fluxes is a critical factor in producing and modifying regional atmospheric circulations (Avissar and Pielke, 1989) and has been a major subject of research during the past two decades (Chehbouni et al., 2000). Nowadays remote sensing algorithms are widely used for estimating these spatially distributed surface fluxes. To validate these algorithms, required ground truth data are directly comparable to the flux estimates obtained from such algorithms. The increasing popularity of using a large aperture scintillometer (LAS) for doing so can be explained by both its ease of operation and relatively low cost as well as by its potential capability of obtaining spatially

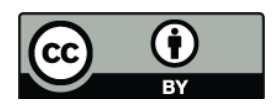

Correspondence to: W. J. Timmermans (timmermans@itc.nl) aggregated flux estimates. However, this validation exercise is not as straightforward as one may hope for, due to mainly two issues that are related to the spatial heterogeneity of both the surface and the fluxes.

Although over homogeneous terrain, this methodology has proven to provide accurate estimates of sensible heat flux (Pauwels et al., 2008; Watts et al., 2000; Meijninger and de Bruin, 2000; McAneney et al., 1995; de Bruin et al., 1995), the first complication arises because of well-known theoretical problems when applying the scintillation technique over a heterogeneous surface (Ezzahar et al., 2007; Lagouarde et al., 2002a; Chehbouni et al., 2000; Bsaïbes et al., 2006).

Apart from these problems that relate to applying the scintillation technique over heterogeneous areas, a second problem relates to the direct comparison between the remote sensing-based and ground-based estimate of sensible heat flux. If the surface is heterogeneous, the signal measured by the sensor, the LAS in this case, depends on which part of the surface has the strongest influence on the sensor and, thus, on the location and size of its so-called footprint (Schmid, 2002). In most natural landscapes, the footprint will contain different landcover types and a successful interpretation of the measured fluxes will depend on an appropriate footprint model (Soegaard et al., 2003). Therefore, the only useful comparison between remote sensing-based and groundbased estimates of sensible heat flux can be done by accounting for heterogeneity within the footprint.

Shuttleworth (1988) argued that the most effective way to synthesize grid-area, weighted average values of surface characteristics, is to use remote sensing techniques to diagnose areas which can be treated as a particular surface type and to compute the average value of the surface characteristics assigned to each component cover weighted by its

Published by Copernicus Publications on behalf of the European Geosciences Union. 
remotely sensed area-average frequency of occurrence. Shuttleworth (1988) stated that "the effective area-average value of land surface parameters is estimated as a weighted average over the component cover types in each grid through that function involving the parameter which most succinctly expresses its relationship with the associated surface flux", which is exactly what we will attempt here.

The objective of the current contribution is to verify the suitability of the LAS for producing area-average estimates of sensible heat flux over heterogeneous terrain and its applicability for validating spatially distributed flux estimates from remote sensing observations. A footprint-weighted approach is proposed in Sect. 2 to aggregate surface characteristics, taking into account, within footprint heterogeneity, the information obtained through remote sensing. The approach is tested on simulated data in Sect. 3 and applied over a very heterogeneous test site in Barrax (Spain) in Sect. 4. A discussion on the results follows in Sect. 5 and the paper is concluded with some remarks in Sect. 6.

\section{Scintillation technique}

In this section, first a summary of the physical background of the LAS measurement is provided, described also in detail in Chehbouni et al. (2000), Lagouarde et al. (2002b) and Wang et al. (1978), valid for the observations over a homogeneous surface. Then a review is provided on typical problems over heterogeneous surfaces, followed by a section dealing with implications for estimating fluxes from LAS observations over a heterogeneous landscape.

\subsection{The homogeneous case}

Large Aperture Scintillometers (LAS) provide a measurement of the structure parameter for the refractive index $C_{N}^{2}$ $\left(\mathrm{m}^{-2 / 3}\right)$ derived from the intensity fluctuations of an optical beam between a transmitter and a receiver. The variance of the natural logarithm of the irradiance $I$ incident at the receiver is given by:

$\sigma_{\ln (I)}^{2}=\overline{[\ln (I)-\overline{\ln (I)}]^{2}}=\int_{0}^{1} C_{N}^{2}(u) W(u) d u$

where the overbar is a spatial averaging, and $W(u)$ is a nonuniform, bell-shaped weighing function:

$$
\begin{aligned}
& W(u)=16 \pi^{2} k \cdot P \cdot \int_{0}^{\infty} K \Phi_{N}(K) \sin ^{2} \\
& \cdot\left(\frac{K^{2} P u(1-u)}{2 k}\right) \cdot\left(\frac{2 J_{1}(x)}{X}\right)^{4} d K
\end{aligned}
$$

where $u(-)$ is the normalized path distance from the transmitter, equal to $x / P$, with $P$ being the path length (m). The optical wave number, $k=2 \pi / \lambda$ and $x=1 / 2 K D u$, where $D$ is the diameter of the receiver/transmitter aperture and $K$ the three-dimensional spatial wave number. $J_{1}$ is a Bessel function of the first kind of order one, and $\Phi_{N}$, the threedimensional Kolmogorov spectrum of the refractive index, which describes the turbulent medium in terms of its Fourier components $K$, is given by:

$\Phi_{N}(K)=0.033 \cdot C_{N}^{2} K^{-11 / 3}$

Integration of Eq. (2) combined with Eqs. (1) and (3), yields the spatial average value of the structure parameter as obtained from a LAS, following Wang et al. (1978):

$\left\langle C_{N}^{2}\right\rangle=1.12 \cdot \sigma_{\ln (I)}^{2} \cdot D^{7 / 3} \cdot P^{-3}$

where the brackets on the left-hand side of the equation indicate a spatial average of the measured refractive index.

Several authors (de Bruin et al., 1993; Green et al., 2001; McAneney et al., 1995) have described the theory in detail by deriving turbulent exchange from scintillation measurements over uniform surfaces, which is summarized here. In the optical domain, when humidity fluctuations in the atmosphere have a much smaller influence on the signal than temperature fluctuations, the structure parameter for temperature, $C_{T}^{2}$ $\left(\mathrm{K}^{2} \cdot \mathrm{m}^{-2 / 3}\right)$ can be derived from $C_{N}^{2}$ as measured by a scintillometer following Wesely (1976):

$C_{T}^{2}=C_{N}^{2}\left(\frac{T_{a}^{2}}{\gamma \cdot p}\right)^{2} \cdot\left(1+\frac{0.03}{\beta}\right)^{-2}$

in which $T_{a}$ represents air temperature $(K), \gamma$ is the refractive index for air $\left(7.9 \cdot 10^{-7} \mathrm{~K} \cdot \mathrm{Pa}^{-1}\right), p(\mathrm{~Pa})$ is the atmospheric pressure and $\beta(-)$ is the well-known Bowen ratio, here used as a correction term for humidity related scintillations. Similarity relationships (Wyngaard et al., 1971) based on MoninObukhov Similarity Theory, provide the possibility to derive sensible heat flux, $H\left(\mathrm{~W} \cdot \mathrm{m}^{-2}\right)$, through the use of the temperature scale, $T_{*}(K)$, following:

$C_{T}^{2}=T_{*}^{2}\left(z-d_{0}\right)^{-2 / 3} \cdot f_{T}\left(\frac{z-d_{0}}{L}\right)$

where $z(\mathrm{~m})$ is the effective height (Hartogensis et al., 2003) of the LAS measurement, $d_{0}(\mathrm{~m})$ the displacement height, $f_{T}$ (-) the universal stability function, and the temperature scale is defined as:

$T_{*}=\frac{-H}{\rho \cdot c_{p} \cdot u_{*}}$

where $\rho\left(\mathrm{kg} \cdot \mathrm{m}^{-3}\right)$ is the density of air, $c_{P}\left(\mathrm{~J} \cdot \mathrm{kg}^{-1} \cdot \mathrm{K}^{-1}\right)$ is the specific heat of air at constant pressure and $u_{*}\left(\mathrm{~m} \cdot \mathrm{s}^{-1}\right)$ is the well-known friction velocity. The form of the stability functions adopted here are taken from Green et al. (2001):

$f_{T}\left(\frac{z-d_{0}}{L}\right)=c_{T 1} \cdot\left(1+c_{T 2} \cdot\left|\frac{z-d_{0}}{L}\right|\right)^{-2 / 3}$

for $\left(z-d_{0}\right) / L<0$ (unstable) 
$f_{T}\left(\frac{z-d_{0}}{L}\right)=c_{T 1} \cdot\left(1+c_{T 3} \cdot\left(\frac{z-d_{0}}{L}\right)^{2 / 3}\right)$

for $\left(z-d_{0}\right) / L>0$ (stable)

where $L(\mathrm{~m})$ is the Monin-Obhukov length, defined as:

$L=\frac{u_{*}^{2} \cdot T_{a}}{g \cdot k \cdot T_{*}}$

in which $g\left(\mathrm{~m} \cdot \mathrm{s}^{-2}\right)$ is the gravitational constant and $k(-)$ the von Karman constant. The constants $c_{T 1}, c_{T 2}$ and $c_{T 3}(-)$ are take equal to 4.9, 6.1 and 2.4, respectively (Wyngaard et al., 1971). There is no general consensus on the stability function for stable conditions (Eq. 8b), however, in this work we use the coefficients proposed by Wyngaard et al. (1971), as mentioned above.

Obtaining the sensible heat flux from a scintillometer measurement over homogeneous terrain, thus, invokes solving $H$ from Eqs. (5)-(9). This requires measurements with a number of additional parameters; air temperature, air pressure, Bowen ratio, displacement height and friction velocity. Since measurements of friction velocity are not generally available, independent windspeed measurements, $u$, at reference height $z_{u}$ may be combined with an estimate of surface roughness length, $z_{0}$, following:

$u_{*}=k \cdot u \cdot\left[\ln \left(\frac{z_{u}-d}{z_{0}}\right)-\psi_{M}\left(\frac{z_{u}-d}{L}\right)\right]^{-1}$

where $\psi_{M}(-)$ is the integrated stability function (Panofsky and Dutton, 1984), to obtain estimates of friction velocity.

Generally an estimation of the aerodynamic properties of the terrain, surface roughness length and displacement height, estimated as a fraction of canopy height, following Brutsaert (1982), ensures an accurate estimate of sensible heat flux over homogeneous terrain.

\subsection{Application to a heterogeneous surface}

When the theory, described above, is applied over a heterogeneous surface, comprising of two or more patches or agricultural fields, additional assumptions need to be made. Besides doubts on the validity of Monin-Obhukov similarity theory below the blending height over a heterogeneous surface, problems exist on how to parameterize an equivalent or areally averaged temperature scale, and friction velocity (Lagouarde et al., 2002b; Ezzahar et al., 2007), as well as how to deal with the nonlinear sensitivity of the scintillometer to $C_{N}^{2}$ along its beam. Lagouarde et al. (2002a) presented an approach for a two-surface composite case where aggregated estimates for displacement height were obtained using:

$$
\langle d\rangle=r \cdot d_{1}+(1-r) \cdot d_{2}
$$

where the brackets indicate a spatial average and $r$ indicates the proportion of surface 1 under the beam of the scintillometer, whereas subscripts 1 and 2 refer to the two surface components, or patches, under the beam of the scintillometer. An estimate for the areal averaged roughness length is obtained from one of the two following schemes:

$\ln \left\langle z_{0}\right\rangle=r \cdot \ln \left(z_{01}\right)+(1-r) \cdot \ln \left(z_{02}\right)$

$\left(\ln \left(\frac{z-<d>}{<z_{0}>}\right)\right)^{-2}=r \cdot\left(\ln \left(\frac{z-d_{1}}{z_{01}}\right)\right)^{-2}$

$+(1-r) \cdot\left(\ln \left(\frac{z-d_{2}}{z_{02}}\right)\right)^{-2}$

A mean windspeed then is obtained according to an aggregation scheme based on a linear transit time for an air parcel along the pathlength, resulting in:

$\langle u\rangle=\frac{u_{1} \cdot u_{2}}{r \cdot u_{2}+(1-r) \cdot u_{1}}$

Integration of the weighing function of the scintillometer from 0 to $r$ and from $(1-r)$ to 1 provides weighting factors, $W_{i}$, with $i$ the component number. They are used to obtain an average value of $C_{N}^{2}$ assumed to originate from the two components following:

$\left\langle C_{N 2}^{2}\right\rangle=W_{1} \cdot C_{N 1}^{2}+W_{2} \cdot C_{N 2}^{2}$

which is then used to derive an aggregated sensible heat flux in a similar fashion as described above. Lagouarde et al. (2002) compared these versus reference values for sensible heat, obtained from sonic measurements at the two surface components weighted following the same approach as in Eq. (11). As such, the reference flux was defined as the average of the component fluxes weighted by the ratio of their contribution to the pathlength of the scintillometer. This yielded a small but systematic overestimation by the scintillometer-based estimates. A sensitivity analysis on a simple model simulating the integration methodology showed that the composition of the pathlength, the contrast in fluxes and, to a lesser extent, the aerodynamic properties of the two surface components induced the deviations between the scintillometer-based estimates and the reference values of sensible heat flux. An underestimation (overestimation) by the LAS depended on whether the largest field in the pathlength was the wettest (driest) part.

A slightly different approach is described by Ezzahar et al. (2007), who estimated $C_{N}^{2}$ at grid scale from component LAS measurements, where the components consisted of an olive orchard with two contrasting fields. Demonstrating that Monin-Obhukov similarity theory applies below the blending height, they obtained a grid-scale sensible heat flux, $<H>$, following:

$\langle H\rangle=r \cdot H_{\mathrm{LAS}-1}+(1-r) \cdot H_{\mathrm{LAS}-2}$

Subscripts 1 and 2 here indicate variables associated with the two surface components, or patches, and $r$ indicates the proportion of surface 1 to the total grid. Simplifying Eq. (15) to:

$\left\langle u_{*} T_{*}\right\rangle=r \cdot u_{* 1} T_{* 1}+(1-r) \cdot u_{* 2} T_{* 2}$ 
and combining Eqs. (5) and (8b) with Eq. (15) an expression for $C_{N}^{2}$ aggregated at grid was obtained:

$$
\left\langle C_{N}^{2}\right\rangle=<y>^{-1} \cdot\left(y_{1} C_{N 1}^{2}+y_{2} C_{N 2}^{2}\right)
$$

with:

$$
y_{i}=\left(r_{i}\right) \frac{u_{* i}\left(1+0.03 \frac{0.03}{\beta_{i}}\right)^{-2} \cdot\left(z_{0 i}-d_{i}\right)^{2 / 3}}{T_{* i} \cdot\left(1+c_{T 2} \frac{\left(z_{0 i}-d_{i}\right)}{L}\right)^{-2 / 3}}
$$

where $i$ is either component 1,2 or indicating the grid-scale average (angular brackets), and $r_{i}=1$ for $\left\langle y>, r_{i}=r\right.$ for $y_{1}$ and $r_{i}=(1-r)$ for $y_{2}$.

Grid-scale averages of displacement height and roughness length are then obtained in a similar way as proposed by Lagouarde et al. (2002a) through Eqs. (11) and (12b), respectively.

In the approach described by Ezzahar et al. (2007), the aggregated, or grid-scale, sensible heat flux reflects an average sensible heat flux over those parts of the grid that are observed.

In their experiment the source areas of the two LAS systems appeared to be approximately equal, rendering $r_{1}$ equal to $r_{2}$ equal to 0.5 in Eqs. (15)-(18). They note, however, that a third LAS, covering the two patches, would not provide a measurement that can be used to validate their aggregation method, since this scintillometer would have a varying contribution of the two patches, depending on wind direction. Moreover, these contributions would be influenced by the weighting function of such a LAS.

\subsection{Footprint implications}

So far, we were mainly treating the heterogeneous surface as a one-dimensional two-component area. However, when measurements are made below the blending height, a portion of the upstream surface, the source area, influences the sensor. Numerous so-called footprint models are described in the literature that relate the measured flux at a certain height to the weighted spatial distribution of the surface fluxes that contribute to the measurement. Meijninger et al. (2002) described that in applying this concept to the LAS, one has to combine the footprint function with the spatial weighting function of the LAS in order to estimate the relative contribution of the surface fluxes to the measured flux.

We used a simple three-dimensional footprint model that calculates the source strength, $F_{x^{\prime}, y^{\prime}}$, for a single observation point, following:

$$
F_{x^{\prime}, y^{\prime}}=\frac{F_{x^{\prime}}}{\sqrt{2 \pi \sigma_{y^{\prime}}}} \cdot e^{-\left(y^{\prime 2} / 2 \sigma_{y^{\prime}}^{2}\right)}
$$

where $\sigma_{y^{\prime}}$ is the cross wind spread in the direction $y^{\prime}$ perpendicular to the wind direction $\left(x^{\prime}\right)$ and $F_{x^{\prime}}$ is the relative contribution per running $\mathrm{m}$ along the wind direction, as:

$$
F_{x^{\prime}}=\frac{u}{u_{*}} \cdot \frac{z_{m}}{k x^{\prime 2}} \cdot e^{-\left(u / u_{*}\right) \cdot\left(z_{m} / k x^{\prime}\right)}
$$

where $k$ is von Karman constant and $z_{m}$ the measuring height. The footprint model, described in detail in Soegaard et al. (2003), is then combined with the weighting function of the LAS to obtain the relative contribution of each of the contributing component surface covers, $r f p_{i}$, where the subscript $i$ refers to a particular surface component. The LAS path is thought to consist of a series of single observation points each for which a single source strength is calculated using Eqs. (19)-(20). Each of these source strengths is then multiplied with the LAS weighting function, $W(u)$. Summation of the individual points, normalized by the total sum of the source areas, then yields the LAS weighted footprint. It should be noted that the footprint model used here is chosen for its relatively simple implementation. In principle, any other footprint model (Schuepp et al., 1990; Horst and Weil, 1992; Schmid, 2002) may be used.

Spatially distributed information on surface aerodynamic properties was entered into this model to account for footprint heterogeneity. This relative footprint-weighted contribution is then used to obtain aggregated displacement height, surface roughness and structure parameter of air following Eqs. (11), (12a), (17) and (18), where $r_{i}$ should be replaced by $r f p_{i}$. The objective here is to obtain an aggregated structure parameter as it would be obtained from a single LAS measurement over different components, as opposed to Ezzahar et al. (2007) who aimed at a grid-scale aggregated flux. To achieve this, $r_{i}$ needs to be replaced by $r f p_{i}$ in Eqs. (11), (12a), (17) and (18).

The approach described above is tested on simulated data in a one-dimensional manner in Sect. 3. A one-dimensional treatment assumes the components are only contributing along the path of the scintillometer. This implies that only the LAS weighting function is influencing the component contribution. The LAS derived sensible heat flux, $H_{\text {sim }}$, is obtained from the prescribed component sensible heat fluxes, $H_{1}$ and $\mathrm{H}_{2}$. The procedure is such that the component structure parameters, $C_{N, i}^{2}$, where $i$ is either 1 or 2 , are calculated from inverting the procedure outlined by Eqs. (5)-(9). These are then weighted according to Eqs. (17) and (18), using $r_{\mathrm{fp}, \mathrm{i}}$ instead of $r_{i}$, to simulate a $<C_{N}^{2}>$ that a LAS would have measured, which is then used to obtain $H_{\text {sim }}$. Following, $H_{\text {sim }}$ is compared to a reference sensible heat flux, $H_{\text {ref. }}$. The reference flux is directly derived from the component fluxes, $H_{1}$ and $H_{2}$, weighted by their relative contribution, following:

$H_{\text {ref }}=r f p_{1} \cdot H_{1}+r f p_{2} \cdot H_{2}$

In Sect. 4 the aggregation approach is then applied in a twodimensional manner, incorporating the spatial distribution of the contributing components. The data used was collected during the SPARC2004 field campaign in Barrax (Spain) and is described in detail in Su et al. (2008). 


\section{Simulation}

The (1-D) case of a composite surface comprising of two plots is simulated. We choose two components with very contrasting sensible heat flux and assumed similar parameter values as used in Lagouarde et al. (2002a). This meant that for plot 1 , we randomly generated sensible heat fluxes between 0 and $50 \mathrm{Wm}^{-2}$ and for plot 2 between 350 and $400 \mathrm{Wm}^{-2}$. The roughness length and displacement height were taken as $1 / 8$ and $2 / 3$ times the canopy height, following Brutsaert (1982), where the canopy heights for the plots were given random heights uniformly distributed between 0.015 and $1.5 \mathrm{~m}$. Windspeed, $u_{\text {ref }}$, chosen at a reference height, $z_{\text {ref }}$ equal to $50 \mathrm{~m}$ to ensure reasonably uniform windspeed, was given random values between 0.5 and $6.0 \mathrm{~ms}^{-1}$, and the contributing areas, $r_{1,2}$, were given random numbers between 0 and 1 , so that their sum was equal to unity. Other parameters were kept constant, available energy (necessary to calculate a Bowen ratio) equal to $450 \mathrm{Wm}^{-2}$ and air temperature, $T_{a}$, equal to $301 \mathrm{~K}$.

These data were input into a simulation (5000 runs) using different aggregation methods. The first simulation followed the approach described in detail in Lagouarde et al. (2002a). Since the reference flux here is derived from the component fluxes weighted by the contributing areas, $r_{1,2}$, in the remainder of this text it is referred to as L-r. A second simulation concerned the same approach, but now with the reference flux defined as in Eq. (21). We will refer to this simulation as L-rfp. The third simulation followed the approach described in Ezzahar et al. (2007), also using the reference flux defined following Eq. (21). Therefore, we will refer to it as E-rfp. The fourth simulation concerning the new approach described in the current contribution, is N-rfp.

Results are presented in Fig. 1, where in the left panels the simulated fluxes are plotted versus the reference fluxes. The right panels show the difference, $H_{\mathrm{sim}}-H_{\text {ref }}$, versus the contributing area, either $r$ (the first simulation) or $r f p$ (the other simulations). A low value for $r$ means a low contribution from surface component 1 . The chosen contrast in sensible heat flux resulted in differences $H_{1}-H_{2}$ ranging from -400 to $-300 \mathrm{Wm}^{-2}$, similar to the range in Lagouarde et al. (2002a). They presented their results composing $H_{\text {ref }}$ from its components by not taking into account the weighting function of the LAS. We have plotted the results in Fig. 1a and 1e, which resembles the "diamond" class in Fig. 10 of Lagouarde et al. (2002a). The results from the second simulation (L-rfp), where $H_{\text {ref }}$ was composed by taking the weighting function of the LAS into account, are shown in Fig. $1 \mathrm{~b}$ and $\mathrm{f}$. Simulation results from the E-rfp simulation are given in Fig. 1c and g, whereas results obtained from the N-rfp approach are given in Fig. 1d and h.

An important difference between the existing approaches is that the first one, Lagouarde et al. (2002a), constructs an aggregated LAS signal, $\left\langle C_{N}^{2}\right\rangle$, from component $C_{N}^{2}$ according to the LAS weighting function. This aggregated sig-
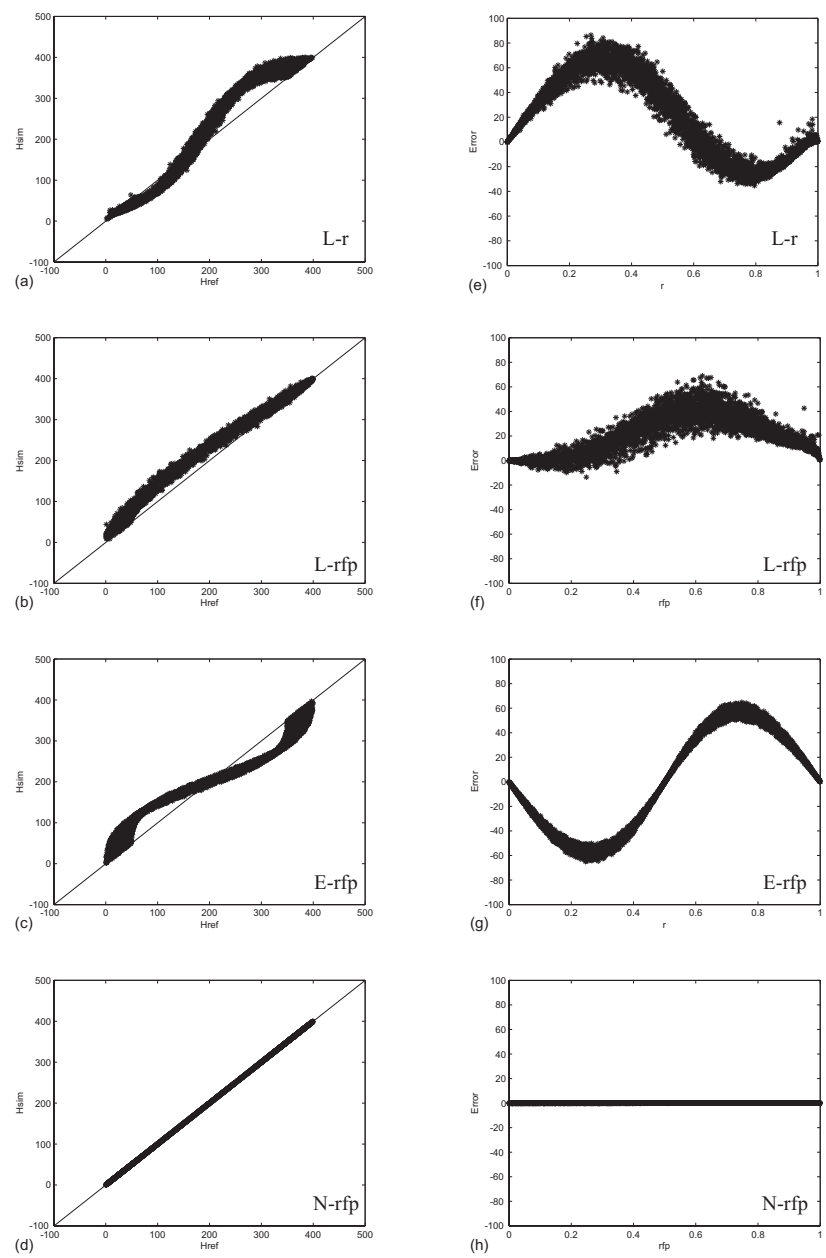

Fig. 1. Simulation results for a two-component surface using aggregation approaches L-r, L-rfp, E-rfp and N-rfp (see main text for additional explanation). Left panels show simulated versus reference fluxes, right panels show the "error", $H_{\text {sim }}-H_{\text {ref }}$, versus the contributing area, $r$ or $r f p$.

nal then represents an LAS measurement of $\langle H>$ over the two areas. The second approach, Ezzahar et al. (2007), constructs an aggregated $<C_{N}^{2}>$, directly from LAS measured component $C_{N}^{2}$ avoiding the weighting function. As such, this $\left\langle C_{N}^{2}\right\rangle$ will yield an $<H>$ that represents a spatially weighted average, or grid-scale average, sensible heat flux.

When $H_{1}<H_{2}$ and $r<(1-r)$, the approach originally suggested by Lagouarde et al. (2002a) yielded an overestimation of $H_{\text {sim }}$ with respect to $H_{\text {ref }}$. This is because the method does take the LAS weighting function, $W(u)$, into consideration for obtaining an aggregated $C_{N}^{2}$, whereas for the calculation of the reference sensible heat flux, $H_{\text {ref }}$, a linear weighing based on the contributing area is assumed. This systematic effect is removed when taking the weighting function into account. However, still deviations, originating from the difference in component aerodynamic characteristics, are noted which can be attributed to the assumption of Eq. (14). 
This problem was solved analytically by Ezzahar et al. (2007) resulting in Eqs. (17) and (18). However, when applying their approach on a LAS signal measured over a two-component contrasting surface, the reference sensible heat flux, $H_{\text {ref }}$, should also be estimated from the component sensible heat fluxes weighted by the weighing function of the LAS. In the case of $H_{1}<H_{2}$ and $r<(1-r)$, the $H_{\text {ref }}$ will be higher than the $H_{\text {sim }}$ since the method does not incorporate the weighting function of the LAS, resulting in an underestimation of $H_{\mathrm{sim}}$. This phenomenon is illustrated in Fig. 1c and g.

When taking the weighting function into account for determining the relative component contribution to the aggregated $\mathrm{C}_{N}^{2}$, as well as to the aggregated aerodynamic properties, the errors reduce to zero (see Fig $1 \mathrm{~d}$ and $\mathrm{h}$ ), meaning that the nature of the scintillometer measurements is properly simulated. It should be noted, though, that when applying the methodology of Ezzahar et al. (2007) and assuming $\mathrm{H}_{\text {ref }}$ originates from a simple linear weighting of the component fluxes, the results are similar to those presented here. However, when utilizing LAS observations for validating spatially distributed flux estimates, the relative contribution of component areas needs to be known. Therefore, in such cases, the footprint calculations as well as the weighting function should be taken into account.

\section{SPARC2004 Experiment}

Observations of water and heat fluxes (Su et al., 2008) were made during the ESA SPARC (SPectra bARrax Campaign) 2004 field experiment conducted at the Las Tiesas Experimental Farm test site at Barrax in the La-Mancha region in Spain, maintained by the Provincial Technical Agronomical Institute (ITAP).

This agricultural area, which is partly irrigated, comprises of land covers ranging from completely bare soil to fully vegetated parcels with canopy heights from several centimetres up to two metres. The area is rather flat and is situated at an average $700 \mathrm{~m}$ a.s.l. The campaign took place from 12 to 21 July when natural surfaces are under water-stress since rainfall is mainly absent during this period. Daily minimum and maximum temperatures measured over the vineyard during the period were 14.3 and $31.6^{\circ} \mathrm{C}$. The prevailing wind directions range from a typically south-eastern direction during morning hours, changing towards a northern direction during late afternoon. This meant that around noon, which coincided with nominal airborne and spaceborne image acquisitions, eastern winds were prevailing.

\subsection{Experimental setup}

A Kipp and Zonen Large Aperture Scintillometer (LAS), formerly Micromet Scientific LAS-150, was installed in the center of the test site. The receiver of the LAS was installed at a height of $5.06 \mathrm{~m}$ at the north-western side of a triangular shaped vineyard ("V1" in Fig. 2.) with sides measuring about $200 \mathrm{~m}$ each, and quite variable canopy heights, depending on age of the crops, ranging from 1.0 up to $2.0 \mathrm{~m}$. The transmitter was positioned at a distance of $784 \mathrm{~m}$ in a harvested wheat field containing at parts dry wheat stubbles of about 0.15 to $0.20 \mathrm{~m}$ height. Installation height here was $4.64 \mathrm{~m}$, yielding an effective measurement height of $4.85 \mathrm{~m}$ of the LAS, since the area is extremely flat. Data were sampled and stored at a $1 \mathrm{~Hz}$ frequency. The demodulated carrier signal was also stored, which was used for determining potential malfunctioning of the LAS. During the post-processing, the data was averaged over $10 \mathrm{~min}$ intervals, a period imposed to provide easy comparison with reference eddy correlation measurements. After the post-processing, a visual check was performed, possiblly due to the relatively short duration of the campaign, and spikes in the observations were removed. The agricultural field directly surrounding the LAS setup consisted of pivot-irrigated, dense-cropped corn fields, bare soil (though alternated by dried hordeum), garlic and grassland, whereas at slightly larger distances a potato field and a forest nursery as well as some other corn fields and a small orchard in the northern part of the area were located. Although most of the bare soil and stubble were very dry, most crops in the area were irrigated. In particular, the relatively large corn fields were heavily irrigated, which at times resulted in stable conditions over the corn during daytime. Due to the prevailing wind directions, we assumed that the main fields influencing the LAS would be "V1", "C2" and "WS", see Fig. 2.

A Gill 3-D sonic anemometer was installed over the vineyard (field "V1") in the vicinity of the LAS receiver, about $50 \mathrm{~m}$ from the northern edge of the vineyard, with local crop heights about $1.1 \mathrm{~m}$. Raw data here was sampled at a $20 \mathrm{~Hz}$ frequency and stored at a portable computer using Campbell's PC208W v.3.3 software. Flux calculations were made using the Alteddy software developed at ALTERRA, Wageningen, The Netherlands and averaged over 10, 30 and $60 \mathrm{~min}$ intervals. Possible low frequency losses resulting from short integration times (Von Randow et al., 2008) could be ruled out as the longer integration times did not bring about any significant increase in flux estimation, see also (Su et al., 2008). A Young 81000 3-D sonic anemometer was installed at a height of $4.4 \mathrm{~m}$ at the western side of field "C2", measuring the fluxes from the corn during prevailing wind directions and at times from the vineyard during western winds. Raw $10 \mathrm{~Hz}$ data of the 3-D ultrasonic anemometer were stored on a portable computer using the program Tourbillon v. 1.0., which has been developed at the Institut National de la Recherche Agronomique (INRA), 


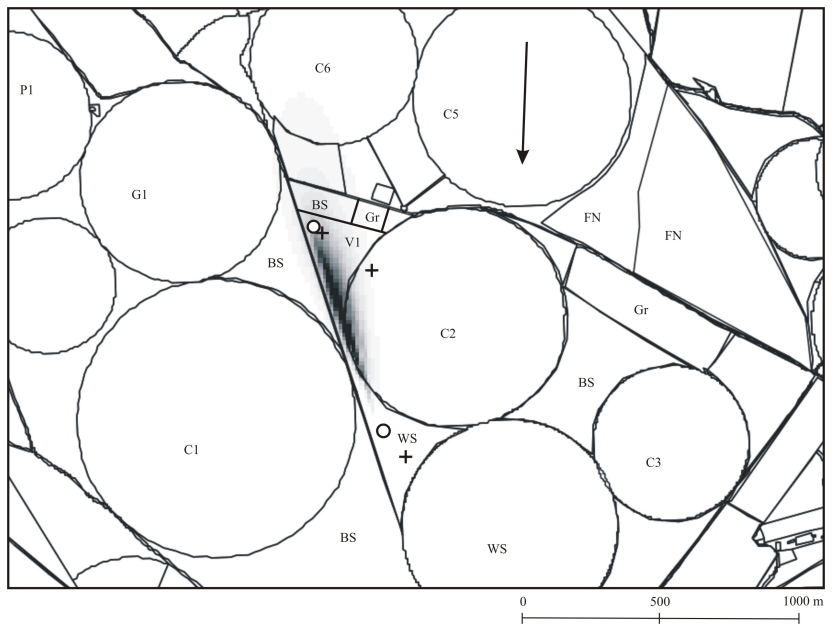

Fig. 2. Map (North oriented) of the experimental set-up at the Las Tiesas experimental farm, showing landcover units and scintillometer weighted observation source area. The LAS is represented by two white circles, and the sonic anemometers by (three) crosses, whereas an arrow indicates the wind direction. Letters represent landcovers vineyard ("V"), grass ("Gr"), corn ("C"), bare soil ("BS"), wheat stubble ("WS"), garlic ("G"), potato ("P") and forest nursery ("FN"), whereas the numbers refer to the respective field numbers.

Bioclimatology Section, Bordeaux, France. Flux calculations have been checked at several time integration lengths (using the classical EDIRE software), without noticing large differences indicating that integration losses were not critical. Due to the rotating pivot irrigation system, the sensor had to be mounted at the edge of the corn field with average crop heights about 1.8 to $2.2 \mathrm{~m}$. A Campbell CA27T, 1-D sonic anemometer was set up at a height of $1.1 \mathrm{~m}$ over the dry wheat stubble field (field "WS"), some $150 \mathrm{~m}$ southeast of the LAS transmitter. The nominal calculation procedure given in the CA27 manual was followed relying on a 10 min covariance calculation with a $10 \mathrm{~Hz}$ scanning time. For the sake of proper comparison, the $10 \mathrm{~min}$ averaging interval data is used on all the data.

As such, the landcover components potentially influencing the LAS observations were monitored during the 6 days, from DOY 197 to 202, in 2004. The observations were made just outside the protected area of the Las Tiesas experimental farm, which gave reason to remove part of the instrumentation during night-time hours. Due to periodic malfunctioning of some of the sonic anemometers, no continuous dataset could be obtained. However, after averaging $10 \mathrm{~min}$ intervals a data set of 69 observations was produced, containing LAS as well as all three sonic measurements, see Table 1.

The temporal evolution of the latter is shown in Fig. 3. This final dataset, containing flux observations on DOY 198, 199, 200 and 202 recorded between 08:00 and 16:00 UTC, was then used for further analysis.

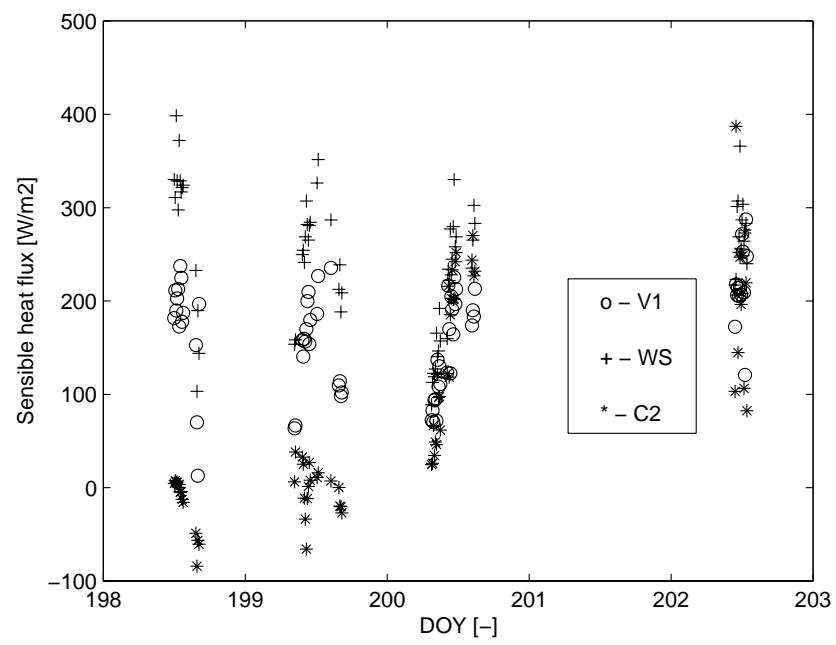

Fig. 3. Quality checked sensible heat fluxes measured by the sonic anemometers over the vineyard, wheat stubble and corn field for the duration of the experiment.

\subsection{Input data}

Parameters needed for estimating $\left.<C_{n}^{2}\right\rangle$ comprise of spatially aggregated available energy, $\left\langle R_{n}-G>\right.$, air temperature $<T_{\text {air }}>$ and friction velocity $<u_{*}>$.

Here the available energy is used for calculating the Bowen ration, which is a correction term in Eq. (5). Since the net radiation and soil heat flux only appear in this corrective factor in an in-direct way, their accuracy is not critical (Lagouarde et al., 2002a). Because the net radiation and soil heat flux could not be measured in all sites, we concentrated on the vineyard measurements. The bulk of the 69 observations were made between 10:00 and 15:00 UTC, during which the available energy varied between $400 \mathrm{Wm}^{-2}$ and $500 \mathrm{Wm}^{-2}$. Therefore, we have adopted a spatially constant average of $450 \mathrm{Wm}^{-2}$.

For $<T_{\text {air }}>$ we have used a measurement obtained at about $5 \mathrm{~m}$ above the ground over the vineyard, which is in the center of the experimental area. In addition, simulations have indicated that spatial variation in air temperature over the area typically are in the order of $1.5 \mathrm{~K}$ (Timmermans et al., 2008), which, we feel, justifies using a single measurement of air temperature here. Moreover, the observation is timeaveraged implying that local variations may have been reduced.

Although the development of internal boundary layers above each surface component may alter the blending height concept slightly (Wieringa, 1986), the blending height concept is used here. Wind speed measurements taken at 4.88 (m) above the ground over the vineyard are transferred to the blending height, which is then taken as a representative aggregate windspeed, $\langle u\rangle$, for the area. Aggregated displacement height and surface roughness length were obtained from Eqs. (11) and (12a), where $r$ is replaced by $r f p$. 
Table 1. Summary of sensible heat flux measurements and instrumentation used.

\begin{tabular}{lllll}
\hline Instrument & $\begin{array}{l}\text { Height } \\
(\mathrm{m})\end{array}$ & Field & $\begin{array}{l}\text { Sampling rate } \\
(\mathrm{Hz})\end{array}$ & $\begin{array}{l}\text { Averaging time } \\
(\mathrm{min})\end{array}$ \\
\hline LAS150-Receiver & 5.06 & $\mathrm{~V} 1$ & 1 & 10 \\
LAS150-Transmitter & 4.64 & $\mathrm{WS}$ & 1 & 10 \\
Young 81000 3-D sonic & 4.4 & $\mathrm{C} 2$ & 10 & 10 \\
Campbell CA27T 1-D sonic & 1.1 & WS & 10 & 10 \\
Gill 3-D sonic & 3.4 & $\mathrm{~V} 1$ & 20 & $10,30,60$ \\
\hline
\end{tabular}

In addition, Eqs. (11) and (12a) were expanded to three components, representing the vineyard, the wheat stubble and the corn field. Spatially distributed information on component characteristics was obtained from a landcover classification based on an ASTER image in its original resolution $(15 \mathrm{~m})$ in combination with a look-up table containing associated canopy height (Van der Kwast et al., 2009). For the wheat the surface roughness length was estimated as the canopy height divided by 8 (Brutsaert, 1982), yielding a value of $0.03(\mathrm{~m})$.

Since the corn crops were very dense, their surface was considerably smoother than could be expected based solely on the height of the canopy (Shaw and Pereira, 1982). Analyzing measurements from the sonic anemometer over the corn during near neutral atmospheric stability conditions, yielded roughness length values between 0.03 and $0.09 \mathrm{~m}$, with an average of $0.068 \mathrm{~m}$. The same procedure was followed for the vineyard. Here the roughness estimates were clustered around two values, depending on the wind direction. Parallel to the row-orientation of the crops, we found roughness values around $0.14 \mathrm{~m}$, whereas perpendicular to the rows values around $0.18 \mathrm{~m}$ were found. Depending on wind direction either one of them was assessed to the vineyard.

Displacement height for the three landcover components was obtained by taking it equal to two-third of the canopy height for the corn and vineyard. For the harvested wheat, a displacement height of $0(\mathrm{~m})$ was taken, since it consisted of rather irregularly spaced wheat stubble, rendering the displacement height principle not applicable.

\subsection{Results}

We have applied the footprint approach using the method presented by Soegaard et al. (2003) combined with the weighting function of the LAS, $W(u)$, following Meijninger et al. (2002). Sensible heat fluxes, $H_{\text {las }}$, were calculated from the scintillation measurements using the aggregated parameters as described in the previous section. Values of the average sensible heat flux obtained with the scintillometer are plotted versus the reference measurements from the sonic anemometers obtained from Eq. (21) in Fig. 4.

To demonstrate the impact of the two-dimensional footprint in the current case, additional calculations were performed, assuming either a homogeneous land cover consist- ing of a vineyard or a wheat field, so-called zero-dimensional approaches, as well as a one-dimensional analysis, assuming a two-component surface consisting of vineyard and wheat stubble. Reference values of sensible heat flux in the homogeneous, or zero-dimensional, cases were taken from the sonic measurements in the respective fields, whereas in the 1-D and 2-D cases they were calculated following Eq. (21). Naturally, adding the corn component, only possible when treating the LAS measurement in a two-dimensional way, both $H_{\text {ref }}$ and $H_{\text {las }}$ decreased as a result of low sensible heat flux for the corn. The upper panels in Fig. 4 shows the results when assuming the LAS measures over a homogeneous surface, consisting entirely of vineyard (left panel) or wheat stubble (right panel). The lower panels show the results for the one-dimensional (left panel) and two-dimensional (right panel) cases. A summary of the results is provided in Table 2 .

It goes without saying that ignoring the influence of the corn field in the aggregation process, obvious for the zeroand one-dimensional cases, for the current case it is not realistic. Large discrepancies between $H_{\text {las }}$ and $H_{\text {ref }}$ are noticed in these cases and correlation coefficients were never exceeding 0.28. Dramatic improvement in both correlation coefficient and RMSD is seen when applying the two-dimensional approach, although still relatively high deviations are noticed.

An attempt is made to further improve these estimates using prior knowledge on flux contrasts between the surface components. This is discussed in the following section.

\section{Discussion}

When aggregating the aerodynamic properties of the surface components, reasonable estimates can be obtained from the canopy heights, yielding the possibility to estimate component friction velocities assuming a wind speed measurement at a sufficient height is available. If further estimates of the contrast between the fluxes of the different components are available, this would potentially improve the estimation of the aggregated flux, since these are then the only remaining parameters determining the relative contributions of $C_{N i}^{2}$ in Eqs. (17)-(18) to $<C_{N}^{2}>$.

We have run aggregations using several different ratios of sensible heat flux which could reasonably be expected for the three land cover components. However, no reasonable results were obtained which is attributed to the high variation of the ratio between the sensible heat fluxes measured over the different fields with time, see also Fig. 3. The fluxes over the vineyard and wheat stubble were rather stable for the days of observation, but rather large fluctuations for the corn were noted, most probably due to irrigation. However, to test whether improvements could be established, we have used the measured ratios between the component fluxes and implemented these in the aggregation scheme. The results for this simulation are displayed in Fig. 5a. 

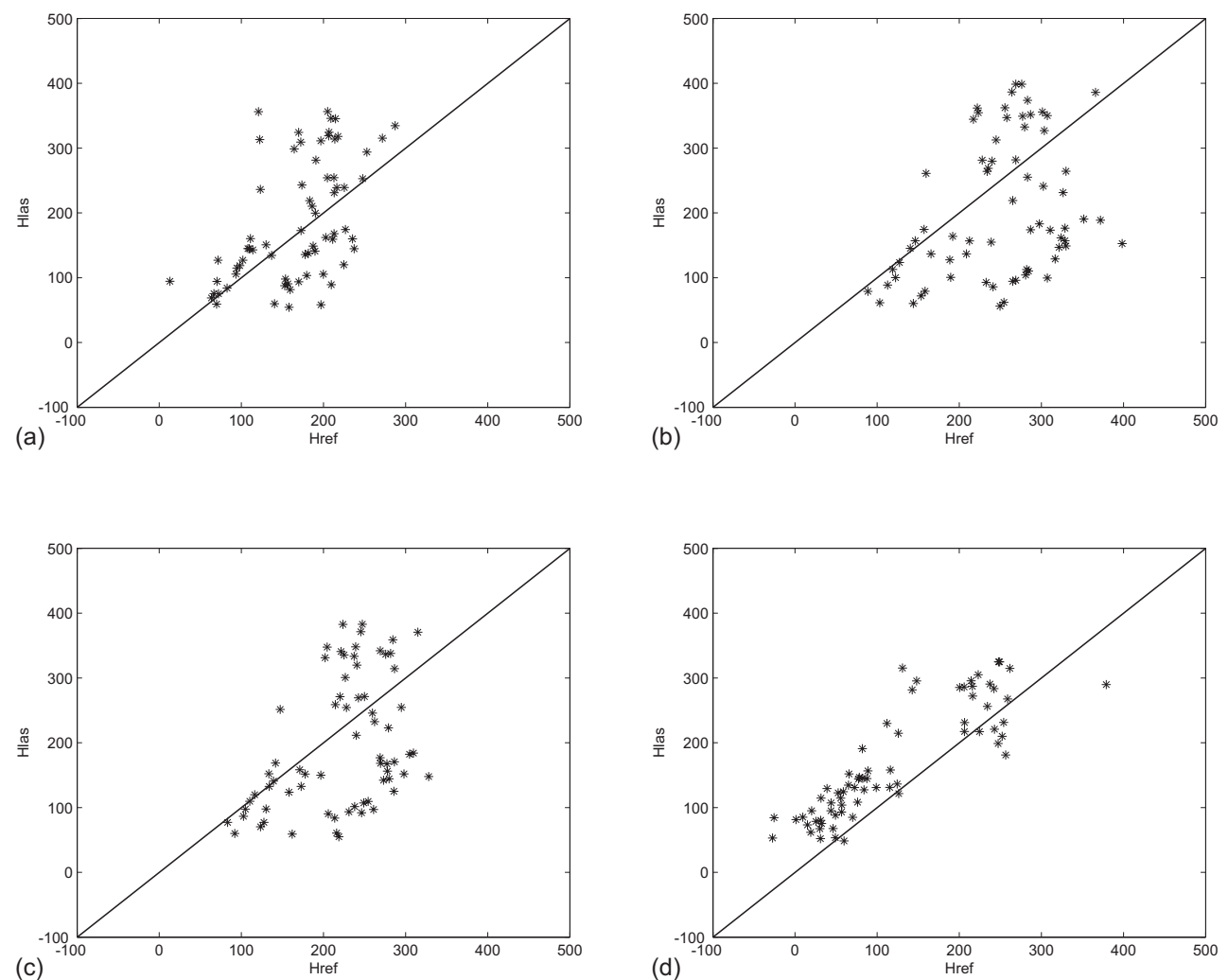

Fig. 4. Comparison between spatially-aggregated sensible heat fluxes derived from sonic anemometers $\left(H_{\text {ref }}\right)$ and scintillometry $\left(H_{\text {LAS }}\right)$. Upper panels show results from the 0-D approach, assuming a homogeneous landuse of either vineyard (a) or wheat stubble (b). The lower panels show results from the 1-D (c) and 2-D (d) approaches, assuming the surface to be composed of vineyard and wheat stubble and vineyard, wheat stubble and corn, respectively.

Table 2. Correlation and Root Mean Squared Differences (RMSD) between aggregated LAS observations and reference values for sensible heat flux using different approaches.

\begin{tabular}{lcc}
\hline Approach & Correlation $\left(R^{2}\right)$ & $\mathrm{RMSD}\left(\mathrm{W} \cdot \mathrm{m}^{-2}\right)$ \\
\hline 0-D (V1) & 0.28 & 81.6 \\
0-D (WS) & 0.12 & 113.7 \\
1-D (V1-WS) & 0.18 & 96.5 \\
2-D (V1-WS-C2) & 0.74 & 67.7 \\
\hline
\end{tabular}

Surprisingly, the results deteriorated with respect to the aggregation not using prior knowledge on flux ratios.

One of the obvious reasons is the simultaneous occurrence of unstable and stable conditions within the footprint of the LAS. Under certain conditions, the irrigated corn fields created an oasis effect in the elsewhere dry and hot surroundings, causing at times stable conditions over the corn. In such cases, which are represented by a low or even negative reference flux, Eqs. (17)-(18) do not hold since the LAS cannot discriminate between upward or downward fluxes. In Fig. 5a these cases are marked by circles. It is clearly noticed that for those cases the deviation is considerably larger than for the cases where only unstable conditions occurred. However, after excluding these cases from the simulation still deviations remained.

Despite careful analysis of the local circumstances and prevailing wind directions when setting up the experiment, it could not be avoided that at certain moments during the campaign the footprint of the LAS included land covers where no reference observations of sensible heat flux were made. Since the aggregation procedure for the aerodynamic properties demands that the sum of the relative contributions of the components is equal to unity, the values for $r f p_{i}$ were normalized by dividing them by the sum of the three components where the actual reference measurements were taken. However, during $73 \%$ of the time the three components contributed for more than $75 \%$ to the total footprint of the LAS, which we believe is acceptable. Under these circumstances, one could think to use thermal remote sensing information to produce estimates of fluxes for components that were not covered by sonic anemometers (Hoedjes et al., 2007). However, this information was not available for the duration of the experiment. 

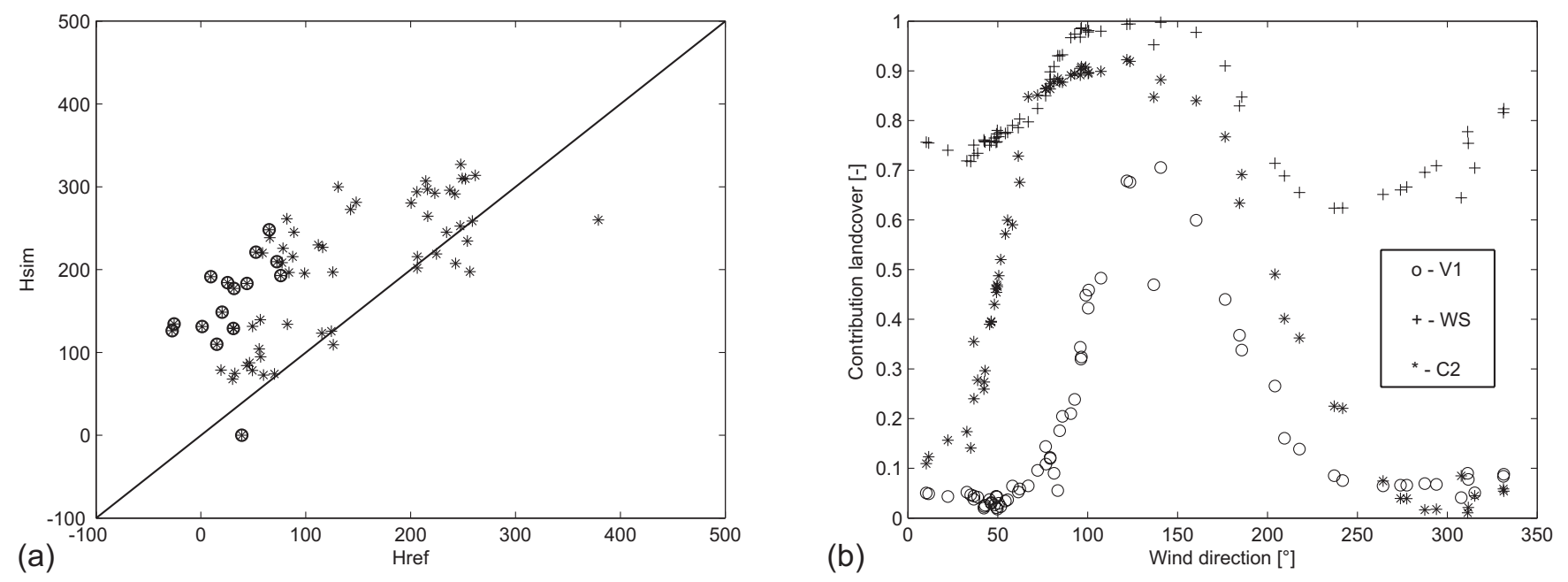

Fig. 5. Simulated versus reference fluxes, assuming the known ratio of component fluxes. Influence of atmospheric stability contrast, stable by circles (a), homogeneity of sonic footprints related to wind direction (b).

Another reason for a mismatch between $H_{\text {las }}$ and $H_{\text {ref }}$ is attributed to incorrect component fluxes. Obviously the sonic measurements are also characterized by their respective footprints, which, like the LAS footprint, is variable in time, depending mainly on wind direction. The instrumentation was installed so that during prevailing wind directions they would produce the most "pure", or highest quality observations. These occurred during the first few days of the experiment as may also be noted from Fig. 3. Unfortunately, wind directions changed during the experiment, resulting in lesser quality EC observations mainly for the vineyard and corn. However, with the change of wind direction to the west, also the corn was almost entirely excluded from the scintillometer footprint, rendering this observation less crucial.

Figure $5 b$ shows the contribution of the field where the sonic anemometers were located relative to the total contributing source area as a function of wind direction. The vineyard is represented by open circles, the wheat stubble by crosses and the corn is represented by closed diamonds. It is clearly noticed that when wind directions are between 100 and $180^{\circ}$, resembling easterly to southerly directions, the footprints were most "pure", or homogeneous.

A plot of the results of the aggregation scheme for estimating $H$ only for wind directions between 100 and $180^{\circ}$ are presented in Fig. 6a. Although for some points a near perfect fit is obtained, there are still a few observations that generate large discrepancies between $H_{\text {las }}$ and $H_{\text {ref. }}$. Since, in the simulations, no discrepancies between $H_{\text {las }}$ and $H_{\text {ref }}$ occurred, the reason here, apart from contrasting stability, must lie in the component fluxes being incorrect, or not pure, or incomplete, meaning the footprint of the LAS contained more covers than only vineyard, wheat stubble or corn.

The discrepancies between $H_{\text {las }}$ and $H_{\text {ref }}$ seem related to the contrast between the component fluxes, as shown in
Fig. 6b. For illustration purposes the maximum ratio, between the corn and the wheat stubble fluxes, is set to 5 in the figure. Because of this, one outlier is not shown, which showed $H$ component-ratios around 200 and a difference between $H_{\text {las }}$ and $H_{\text {ref }}$ equal to $88.5 \mathrm{Wm}^{-2}$. It appears that generally a larger contrast between the component fluxes invokes larger discrepancy between $H_{\text {las }}$ and $H_{\text {ref }}$. There seems to be one exception to this, which is the point with the highest error. However, on inspection we learnt that this point had about $20 \%$ of its footprint not covered by any of the three surface components measured by a sonic anemometer. Moreover, the sonic anemometer of the vineyard for this particular observation only had a $48 \%$ contribution from the vineyard itself, despite a favourable wind direction.

A threshold value seems to be present at a contrast ratio of about 2. Below this value differences between $H_{\text {las }}$ and $H_{\text {ref }}$ are within $20 \mathrm{Wm}^{-2}$, above this value discrepancies rapidly increase. This indicates that when the contrast of surface fluxes for different landcover components were too large (i.e. the ratio is larger than 2), the LAS measurement experienced problems.

\section{Conclusions}

A methodology is proposed to produce LAS-derived areaaverages of sensible heat fluxes suitable for validating spatially distributed models that estimate surface fluxes by remote sensing observations. The soundness of the method is demonstrated by reproducing reference fluxes from component fluxes. Although model results were considerably better than using traditional approaches when applied over the very heterogeneous Barrax test site, some complications are noticed. 


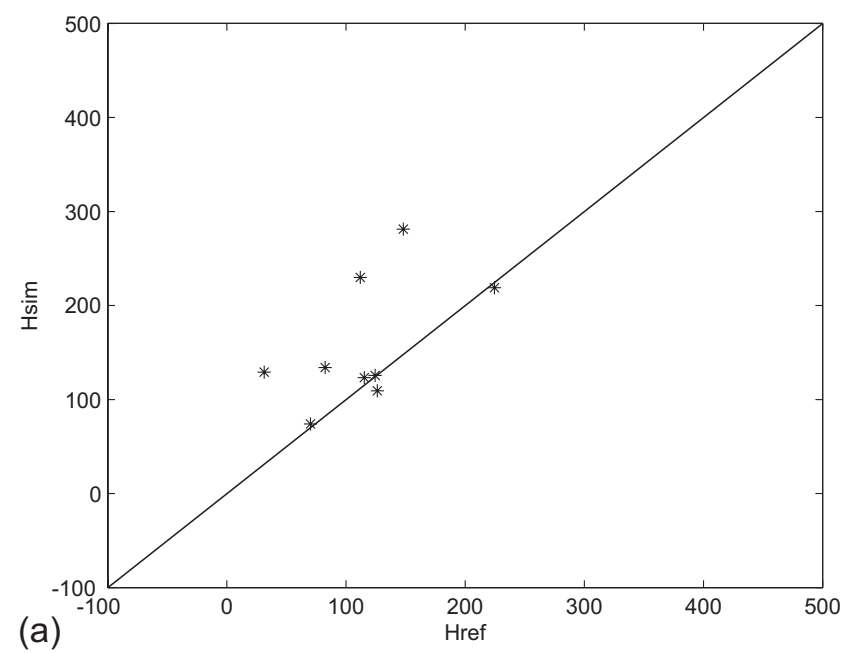

Fig. 6. Simulation results from the N-rfp approach, during south-eastern wind directions (a) and discrepancy between Hlas and Href in relation to component flux contrast (b), between the corn and the wheat stubble.

These were partly due to the nature of the available data. First of all, there is the well-known problem of energy balance closure (Foken, 2008) associated with eddy covariance measurements. Although no major low-frequency losses were noticed when analyzing the vineyard data, there may have been such effects over the wheat stubble or corn.

In addition, during a limited number of observations both stable and unstable conditions occurred within the footprint of the LAS. Due to the nature of the measurement technique, the LAS is not able to distinguish between these conditions, consequently the method does not work and the LAS estimates deviated from the reference values under these circumstances. Though limited in number, during some moments wind directions were such that the footprint of the LAS encompassed land cover units where no reference observations of sensible heat flux were available. The same phenomenon, changing wind-direction, at times caused the footprint of the reference observations not to be homogeneous. Obviously this can hardly be avoided when dealing with agricultural patches under natural conditions. However, when the contrast between landcover components is not too large, deviations between LAS based estimates and reference values were within $20 \mathrm{Wm}^{-2}$.

Acknowledgements. This work has been partly funded through ESA 18307/04/NL/FF. We would like to thank Ambro Gieske from ITC for his help in the installation and maintenance of the scintillometer ground station and Li Jia and Jan Elbers from ALTERRA for their help in the installation and maintenance of the sonic anemometer ground stations and the processing of the eddy correlation data.

Edited by: J. Wen

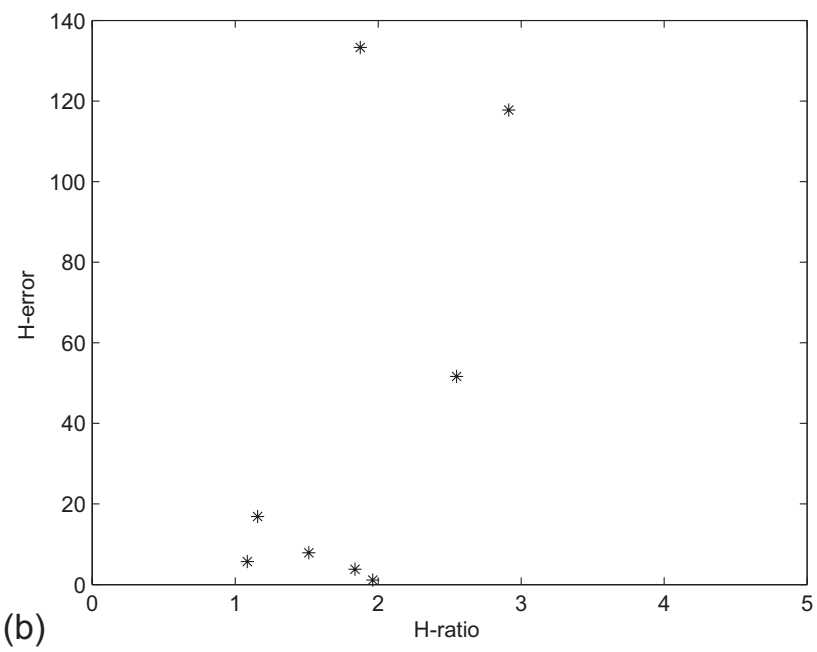

(b)

\section{References}

Avissar, R. and Pielke, R. A.: A parameterization of heterogeneous land surfaces for atmospheric numerical models and its impact on regional meteorology, Mon. Weather Rev., 117, 2113-2136, 1989.

Brutsaert, W.: Evaporation into the atmosphere, Reidel, Dordrecht, The Netherlands, 299 pp., 1982.

Bsaïbes, A., Prévot, L., Voltz, M., Lagouarde, J.-P., and Irvine, M.: Modelling evapotranspiration at the watershed scale using a multi-local approach, European Meteorological Society, 6th EMS / 6th ECAC, Ljubljana, Slovenia, 4-8 September 2006, 2006.

Chehbouni, A., Watts, C., Lagouarde, j.-P., Kerr, Y. H., Rodriguez, J.-C., Bonnefond, J.-M., Santiago, F., Dedieu, G., Goodrich, D. C., and Unkrich, C.: Estimation of heat and momentum fluxes over complex terrain using a large aperture scintillometer, Agr. Forest. Meteorol., 105, 215-226, 2000.

de Bruin, H. A. R., Kohsiek, W., and Hurk, B. J. J. M. v. d.: A verification of some methods to determine the fluxes of momentum, sensible heat, and water vapour using standard deviation and structure parameter of scalar meteorological quantities, Bound.Lay Meteorol., 63, 231-257, 1993.

de Bruin, H. A. R., Hurk, B. J. J. M. v. d., and Kohsiek, W.: The scintillation method tested over a dry vineyard area, Bound.-Lay Meteorol., 76, 25-40, 1995.

Ezzahar, J., Chehbouni, A., Hoedjes, J. C. B., and Chehbouni, A.: On the application of scintillometry over heterogeneous grids, J. Hydrol., 334, 493-501, 2007.

Foken, T.: The energy balance closure problem: an overview, Ecol. Appl., 18, 1351-1367, 2008.

Green, A. E., Astill, M. S., McAneney, K. J., and Nieveen, J. P.: Path-averaged surface fluxes determined from infrared and microwave scintillometers, Agr. Forest. Meteorol., 109, 233-247, 2001.

Hartogensis, O. K., Watts, C. J., Rodriguez, J.-C., and de Bruin, H. A. R.: Derivation of an effective height for scintillometers: 
La Poza Experiment in Nortwest Mexico, J. Hydrometeorol., 4, 915-928, 2003.

Hoedjes, J. C. B., Chehbouni, A., Ezzahar, J., Escadafal, R., and de Bruin, H. A. R.: Comparison of large aperture scintillometer and eddy covariance measurements: Can thermal infrared data be used to capture footprint-induced differences?, J. Hydrometeorol., 8, 144-159, 2007.

Horst, T. W. and Weil, J. C.: Footprint estimation for scalar flux measurements in the atmospheric surface layer, Bound.-Lay Meteorol., 59, 279-296, 1992.

Lagouarde, J.-P., Bonnefond, J.-M., Kerr, Y. H., McAneney, K. J., and Irvine, M.: Integrated sensible heat flux measurements of a two-surface composite landscape using scintillometry, Bound.Lay Meteorol., 105, 5-35, 2002a.

Lagouarde, J.-P., Jacob, F., Gu, X. F., Olioso, A., Bonnefond, J.M., Kerr, Y., Mcaneney, K. J., and Irvine, M.: Spazialization of sensible heat flux over a heterogeneous landscape, Agronomie, 22, 627-633, 2002b.

McAneney, K. J., Green, A. E., and Astill, M. S.: Large-Aperture Scintillometry: the homogeneous case, Agr. Forest. Meteorol., 76, 149-162, 1995.

Meijninger, W. M. L. and de Bruin, H. A. R.: The sensible heat fluxes over irrigated areas in western Turkey determined with a large aperture scintillometer, J. Hydrol., 229, 42-49, 2000.

Panofsky, H. A. and Dutton, J. A.: Atmospheric Turbulence: Models and Methods for Engineering Applications, John Wiley \& Sons, New York, USA, 397 pp., 1984.

Pauwels, V. R. N., Timmermans, W. J., and Loew, A.: Comparison of the estimated water and energy budgets of a large winter wheat field during AgriSAR 2006 by multiple sensors and models, J. Hydrol., 349, 425-440, doi:10.1016/j.jhydrol.2007.11.016, 2008.

Schmid, H. P.: Footprint modeling for vegetation atmosphere exchange studies: a review and perspective, Agr. Forest. Meteorol., 113, 159-183, 2002.

Schuepp, P. H., Leclerc, M. Y., Macpherson, J. I., and Desjardins, R. L.: Footprint prediction of scalar fluxes from analytical solutions of the diffusion equation, Bound.-Lay Meteorol., 50, 355-373, 1990.

Shaw, R. H. and Pereira, A. R.: Aerodynamic roughness of a plant canopy: A numerical experiment, Agricultural Meteorology, 26, 51-65, 1982.
Soegaard, H., Jensen, N. O., Boegh, E., Hasager, C. B., Schelde, K., and Thomsen, A.: Carbon dioxide exchange over agricultural landscape using eddy correlation and footprint modelling, Agr. Forest. Meteorol., 114, 153-173, 2003.

Su, Z., Timmermans, W. J., Gieske, A. S. M., Jia, L., Elbers, J. A., Olioso, A., Timmermans, J., Van der Velde, R., Jin, X., Van der Kwast, H., Sabol, D., Sobrino, J. A., Moreno, J., and Bianchi, R.: Quantification of land-atmosphere exchanges of water, energy and carbon dioxide in space and time over the heterogeneous Barrax site, Int. J. Remote Sens., 29, 5215-5235, doi:10.1080/01431160802326099, 2008.

Timmermans, W. J., Bertoldi, G., Albertson, J. D., Olioso, A., Su, Z., and Gieske, A. S. M.: Accounting for atmospheric boundary layer variability on flux estimation from RS observations, Int. J. Remote Sens., 29, 5275-5290, doi:10.1080/01431160802036383, 2008.

Van der Kwast, J., Timmermans, W. J., Gieske, A. S. M., Su, Z., Olioso, A., Jia, L., Elbers, J., Karssenberg, D., and de Jong, S.: Evaluation of the Surface Energy Balance System (SEBS) applied to ASTER imagery with flux-measurements at the SPARC 2004 site (Barrax, Spain), Hydrol. Earth Syst. Sci., 13, 13371347, 2009, http://www.hydrol-earth-syst-sci.net/13/1337/2009/.

Von Randow, C., Kruijt, B., and Holtslag, A. A. M.: Exploring eddy-covariance and large-aperture scintillometer measurements in an Amazonian rain forest, Agr. Forest. Meteorol., 148, 680690, 2008.

Watts, C. J., Chehbouni, A., Rodriguez, J.-C., Kerr, Y. H., Hartogensis, O., and de Bruin, H. A. R.: Comparison of sensible heat flux estimates using AVHRR with scintillometer measurements over semi-arid grassland in northwest Mexico, Agr. Forest. Meteorol., 105, 81-89, 2000.

Wieringa, J.: Roughness-dependent geographical interpolation of surface wind speed averages, Q. J. R. Meteorol. Soc., 112, 867889, 1986.

Wyngaard, J. C., Izumi, Y., and Collins, S. A.: Behavior of the refractive-index-structure parameter near the ground, J. Opt. Soc. Am., 61, 1646-1650, 1971. 